\title{
Evaluation of per-operative cough stress test during transobturator mid-urethral sling surgery
}

\author{
Abdulmuttalip Simsek ${ }^{1}$, Sinan Levent Kirecci ${ }^{2}$, Goksel Bayar ${ }^{2}$, Kaya Horasanli ${ }^{2}$, Faruk Ozgor ${ }^{3}$, \\ Zafer Gokhan Gurbuz ${ }^{3}$ \\ ${ }^{1}$ Bakirkoy Sadi Konuk Research and Training Hospital, Department of Urology, Turkey; \\ ${ }^{2}$ Sisli Etfal Research and Training Hospital, Department of Urology, Turkey; \\ ${ }^{3}$ Haseki Research and Training Hospital, Department of Urology, Turkey.
}

This study has been presented in EAU 2015 Meeting in Madrid.

\begin{abstract}
Summary Purpose: Currently, it is unclear how the mesh tension should be adjusted on the transobturator tape surgery (TOT) for improving continence. The aim of this study was to evaluate the effects of per-operative cough stress test on TOT.

Materials and methods: Between March 2007 and December 2011, 206 women with SUI were enrolled in this study. Patients were randomly categorized to treatment with TOT (96) or TOT with cough stress test (110). The IIQ-7 and the UDI-6 were used to identify satisfaction level. At the end of 1st year, two groups were compared patient characteristics, operation time, duration of hospital stay, cure and complication rates.

Results: The cure rate was $84.37 \%$ 81/96) versus $83.63 \%$ (92/110) in TOT and TOT with cough test groups, respectively. Postoperatively ten patient (10/110, 9.09\%) suffered voiding difficulties ( $>250 \mathrm{ml}$ residual urine) in TOT with cough stress test group. Five patients were discharged with transurethral catheter, whereas, in traditional TOT group, two patients $(2 / 96,2.1 \%)$ had transient postoperative voiding difficulty and two patients were treated with repeated catheterization for 1 week $(p<0.05)$. Postoperative groin pain was present in 7/96 (8\%) versus $24 / 110(22 \%)$ in TOT and TOT with cough test groups, respectively $(p<0.05)$. TOT with cough stress test group had an higher rate of complications like, retention of urine, necessitating to cut the tape, mesh erosion and pain in groin or leg. No patient had resistant voiding difficulty or prolonged urinary retention ( $>1$ week) in traditional TOT group. Conclusions: We believe that per-operative cough stress test leads to overtreatment of stress urinary incontinence when the complication rates were considered.
\end{abstract}

KEY WORDS: Cough stress test; Transobturator tape; Stress urinary incontinence (SUI).

Submitted 26 April 2017; Accepted 26 April 2017

\section{INTRODUCTION}

Stress urinary incontinence (SUI) is a condition of involuntary urine leakage due to increased abdominal pressure without detrusor muscle contraction and affect nearly 25\% women population all around the world (12). Further, $4 \%$ of women will undergo SUI surgery in their lifespan (3). Since introduction of urology practise by Delorme, transobturator tape (TOT), has became a most preffered method for the treatment of SUI (4-5). In addition to short learning curve, decreased operative time and hospitalisation time, TOT has a high success rate up to $90 \%$ with lower complication rate (6-7). Although TOT is a safe and favorable for surgery for SUI, success of procedure is related with age, body mass index (BMI), diabetes mellitus, intrinsic sphincter deficiency and concomitant prolapsus surgery (8-9). Also urodynamic parameters including $Q_{\max }$, maximum urethral closure pressure and Valsalva leak point pressure have effects on operation success (10). Additionally, achieve adequate mesh tension is the one of most important point to prevent urinary incontinence. For assessment of the mesh tension, cough stress test (CST) is used intreoperatively while TOT procedure (11). As less tension is associated with leaving the patient incontinent, more tension may cause voiding disorders (12).

In this study, we evaluated affect of CST on TOT procedure success rate and patients quality of life with using the Incontinence Impact Questionnaire and Urinary Distress Inventory Questionnaire. Also we assessed the effect of the adjustment of mesh tension with using CST on postoperative voiding disorders.

\section{MATERIALS AND METHODS}

From March 2007 to December 2011, 206 patients diagnosed with either pure SUI or mixed incontinence with predominance SUI symptoms in two urogynecologic centers were enrolled into the study. Patients were randomly categorized to two groups as TOT procedure without using CST (Group 1) and TOT procedure with using CST (Group 2).

Full medical histories and bladder diary were requested from all patients. Demographic characteristics of patients, including age, BMI, number of pregnacies and comorbidities were recorded. Physical examination including stress test and Q-tip test were performed. Urine analysis, urine culture and urinary ultrasonography for measurement of post voiding residue were completed. In the urodynamic assessment, filling cystometry, uroflowmetry and abdominal leak point pressure were evaluated before the TOT procedure. Intrinsic sphincter deficiency (ISD) was defined as maximal urethral clossure pressure of $20 \mathrm{~cm} \mathrm{H20}$ or less and urethral mobility is defined as Q-tip test results of 300. The $1 \mathrm{~h}$ pad 
weighing test was used to define SUI as a loss of $1 \mathrm{gr}$ of urine in $1 \mathrm{~h}$, as explained by the EAU guidelines on urinary incontinence. Severety and impact of incontinence on quality of life were analysed by using Incontinence Impact Questinnaire (IIQ-7) and the Urinary Distress Inventory (UDI-6). Patients with overactive bladder, neurogenic bladder, immobile urethra, gynecologic malignancies and concomitant prolapsus surgeries were excluded from the study. All procedure were performed by two exprienced surgeon under spinal or epidural anesthesia. After placing mesh, mesh tension was adjusted by using a right angle clamp or long scissor. Mesh tension was assessed by CST in group 2 and if necesssary mesh tension was reduced or increased. Duration of operation, hospitalisation day, intraoperative and post operative complications were registered as well. The first day after operation, the Foley catheter was removed. Uroflowmetry and post voiding residue were evaluated before discharged. If patient inability of voiding or post voiding residue was > $250 \mathrm{cc}$, Foley catheter was indwelled again for a week. Voiding disorders were defined as postoperative voiding difficulties and pain while voiding, high post voiding residue $(>250 \mathrm{ml})$ and retention of urine needed catheterization or mesh cutting. Follow up visits were scheduled on $7^{\text {th }}$ day, $1^{\text {st }}$ month and $1^{\text {st }}$ year. At the end of $1^{\text {st }}$ year, the two groups were compared in relation to patients characteristics, operation time, cure and complication rates.

\section{Statistical analysis}

Data analysis was performed using the software SPSS ${ }^{\circledR}$ version 13.0 for Windows (SPSS Inc., Chicago, IL, USA). Data are presented as number, mean, and standard deviation, and comparisons were performed using the Chisquare test and Mann Whitney U test.

\section{RESULTS}

In 96 patients TOT procedure was performed without CST (Group 1) and in other 110 patients CST was done (Group 2). The mean age and BMI of 206 patients was $52.3 \pm 9.2$ years and $27.8 \pm 3.6 \mathrm{~kg} / \mathrm{m}^{2}$, respectively.

Most common comorbidities were smoking (in 52/ 206,25.2\%) and diabetes mellitus (DM)(in 27/206, $13.1 \%)$.

Preoperative characteristics of patients and physical examination findings were summarized in Table 1.

The mean operation time was $26.4 \pm 8.4$ minutes. None of patients required blood transfusion. Duration of hospital stay was similar between two groups. Any lethal intraoperative or postoperative complication occured. The most common postoperative complaints were voiding difficulties and pain. Postoperatively, ten patients (9.09\%) suffered voiding difficulties in group 2, five patients were discharged with transurethral catheter, whereas, in group 1 , two patients $(2.1 \%)$ had transient voiding difficulty and two patients were treated with repeated catheterization for 1 week $(p<0.05)$.

Postoperative groin pain was present in 7 patients (8\%) versus 24 patients (22\%) in group 1 and in group 2, respectively ( $\mathrm{p}<0.05$ ). No patient had resistant voiding difficulty or prolonged urinary retention (>1 week) in
Table 1.

Demographic characteristics of patients.

\begin{tabular}{|l|c|}
\hline Parameters & Mean \pm standard deviation \\
\hline Age (years) & $52.3 \pm 9.2$ \\
\hline BMI $\left(\mathrm{kg} / \mathrm{m}^{2}\right)$ & $27.8 \pm 3.6$ \\
\hline $\mathrm{DM}$ & $27 / 206(13.1 \%)$ \\
\hline Smoking & $52 / 206(25.2 \%)$ \\
\hline HT & $22 / 206(10.67 \%)$ \\
\hline
\end{tabular}

Table 2.

Postoperative parameters in Group 1 and Group 2.

\begin{tabular}{|lcc|}
\hline & Group 1 & Group 2 \\
\hline Number of patients & 96 & 110 \\
\hline Cure rate & $84.37 \%(81 / 96)$ & $83.63 \%(92 / 110)$ \\
\hline Voiding difficulty & \\
( $\geq 250$ ml post voiding residue $)$ & $(2 / 96,2.1 \%)$ & $(10 / 110,9.09 \%)$ \\
\hline Postoperative pain & $(7 / 96,8 \%)$ & $(24 / 110,22 \%)$ \\
\hline Mesh excision & - & 2 \\
\hline Mesh erosion & - & 1 \\
\hline IIQ-7 & $22.8 \pm 2.7$ & $23.2 \pm 1.9$ \\
$\quad$ Preoperative & $3.8 \pm 1.8$ & $3.4 \pm 1.4$ \\
$\quad$ After first week & $2.7 \pm 1.5$ & $2.5 \pm 1.2$ \\
$\quad$ After first year & $\mathbf{0 . 0 0 1}$ & $\mathbf{0 . 0 0 1}$ \\
$\quad$ P value & $13.7 \pm 1.9$ & $14.1 \pm 1.7$ \\
UDI-6 & $1.7 \pm 0.8$ & $1.9 \pm 0.9$ \\
Preoperative & $1.9 \pm 0.4$ & $2.0 \pm 0.6$ \\
After first week & $\mathbf{0 . 0 0 1}$ & $\mathbf{0 . 0 0 1}$ \\
$\quad$ After first year & & \\
P value & & \\
\end{tabular}

group 1. Mesh excision was performed in 2 patients in group 2. The mean follow up period was 16.4 (12.221.3) months with no significant difference between groups. The cure rate was $84.37 \%(81 / 96)$ versus 83.63\% (92/110) in group 1 and group 2, respectively (at the end of $1^{\text {st }}$ year ). All women completed the IIQ-7 and UDI-6 questionnaire at the first year follow up. The symptoms scores were significantly better at follow up, when compared to preoperative assesment (Table 2).

\section{Discussion}

According to DeLancey and Asthon-Miller, damage of pelvic floor muscle and endopelvic fascia, the supportive layer under urethra, is related with delayed closure of urethral lumen $(13,14)$. If abdominal pressure increase as in cough, urethra is displaced in a dorsocaudal line and the anterior edge of urethra move longer interval than posterior edge of urethra, so SUI would be occur (15). To prevent the movement of urethra and support urethra against increased abdominal pressure, polyprolen mesh is placed in the obturator foramen in TOT procedure with a route of the trocar that avoid potential complications as bladder, bowel and vessels injuries (16). Stav et al. demonstrated a $86 \%$ success rate after TOT surgery in their series of 1225 patients (17). Some surgeon reported up to $91 \%$ cure rate after one year follow up (18). In this study, we achive $84 \%$ cure rate after one year follow up period.

To assess mesh tension intraoperatively, some maneu- 
vers were developed. Some authors apply manual suprapubic pressure or the Credè maneuver on full bladder to create conditions simulating increased intra-abdominal pressure (19). However, standardization of this methods is difficult and affected by surgeon experience and patients BMI. To date, CST is the most preferred method to adjust mesh tension intraoperatively in mid urethral sling surgeries until patient does not leak urine (20). There only few reports about the effect of CST on TOT success but technique and results of CST on TVT are well described and there is no reason to believe CST will have different characteristic between TVT and TOT. Murphy has demonstrated significant improvement in SUI after TVT procedure with CST (21). In contrast, Lavy et al. compared women who undergone TVT with CST and without CST and reported no diffrence in success rate (22). In this study we found $84.37 \%$ (81/96) versus $83.63 \%$ (92/110) success rate of TOT without and with CST, respectively. Our results demostrated that CST does not affect on TOT success.

Voiding dysfunction is one of the most common complication of mid urethral sling surgeries that requires surgical intervention (23). However, there is no standard definition of voiding dysfunction after TOT making difficult to compare the results of different studies. In literature, postoperative retention rates in TOT were between $2.0 \%$ and $10 \%(1,10,19)$. According to Ulmsten, minimal tissue dissection, appropriate positioning of the sling and proper mesh tension were the essential for prevention of urinary retention (24). Schreiner et al. reported that performing Valsalva maneuver during preoperative assessment increased voiding dysfunction nearly seven fold (25). Similarly, we believe that intraoperative CST leads to more mesh tension with associated postoperative voiding disorders.

Preoperative urodynamic parameters are considered important to estimate TOT success and voiding disorders. Kawashima et al. reported that preoperative detrusor contractility failure is significantly related with postoperative voiding difficulty (26). Dawson found that preoperative flow urine flow and low peak urinary flow were associated with postoperative voiding disorders (27). On the other side, Mostafa and Lemack showed that there were no urodinamic parameter to predict postoperative voiding disorders $(28,29)$. In our study urodynamic assessment were evaluated before the TOT procedure.

Most voiding dysfunction after TOT are transient and improved with intermittent catheterization, behavioral or drug therapy (30). If these treatments fail, tape incision is the best way to solve voiding problem. However, SUI recurs in almost $60 \%$ of patients (31). In our study, among patients which had TOT performed without CST, two patients (2.1\%) had transient voiding difficulties and two patient were treated with repeated catheterization for 1 week. Postoperatively ten patient (9.09\%) suffered voiding difficulties in TOT with CST group and five patients were discharged with transurethral catheter. Mesh excision was performed in two patients and these patients suffered from SUI again.

Incontinence-related quality of life is measured with UDI-6 and IIQ-7, as they can be validated in the Turkish population (32). Heinonen et al. used them to assess the outcome of TOT, and confirmed a significant improvement in quality of life (33). Another large study evaluated quality of life in women who underwent TOT, with a 1-year follow-up. Postoperatively, UDI-6 and IIQ-7 were shown to be improved, so the authors concluded that the TOT procedure significantly improved health-related symptoms during daily life (34). In this study, there were benefits in postoperative scores with each assessment tool. We also concluded that TOT surgery improved quality of life at the first year follow-up.

This study had some limitations. First we did not assess preoperative incontinence grade and included it in statical analysis. Further we did not have postoperative urodinamic parameters such as detrusor pressure, flow rate and urethral resistance to compare with preoperative assessment. Small number of patients and short-term follow-up are other limitations of the study.

Our study showed that TOT is a safe and effective treatment modality for SUI. Additionally, we believe that perioperative CST leads to overtreatment of stress urinary incontinence when the complication rates were considered.

\section{References}

1. Bullock TL, Ghoniem G, Klutke CG, Staskin DR. Advances in female stress urinary incontinence: mid-urethral slings. BJU Int 98. 2006; Suppl 1:32-40.

2. Minassian VA, Drutz HP, Al-Badr A. Urinary incontinence as a worldwide problem. Int J Gyneco Obstet. 2003; 82:327-338.

3. Barber MD, Kleeman S, Karram MM, et al. Risk factors associated with failure 1 year after retropubic and transobturator midurethral slings. Am J Obstet Gynecol. 2008; 199:666.e1-666.e7.

4. Delorme E, Droupy S, de Tayrac R, Delmas V. Transobturator tape (Uratape) A new minimally-invasive procedure to treat female urinary incontinence. Eur Urol. 2004; 45:203-207.

5. Novara G, Artibani W, Barber MD, et al. Updated systematic review and meta-analysis of the comparative data on colposuspensions, pubovaginal slings, and midurethral tapes in the surgical treatment of female stress urinary incontinence. Eur Urol. 2010; 58:218-238

6. Giberti C, Gallo F, Cortese P, Schenone M. Transobturator tape for treatment of female stress urinary incontinence: Objective and subjective results after a mean follow-up of two years. Urology. 2007; 69:703-707.

7. Poza JL, Pla F, Sabadell J, et al. Trans-obturator suburethral tape for female stress incontinence: A cohort of 254 women with 1-year to 2-year follow-up. Acta Obstet Gynecol Scand. 2008; 87:232-239.

8. Long CY1, Hsu CS, Wu MP, et al. Comparison of tension-free vaginal tape and transobturator tape procedure for the treatment of stress urinary incontinence. Curr Opin Obstet Gynecol. 2009; 21:342-7.

9. Latthe PM, Foon R, Toozs-Hobson P. Transobturator and retropubic tape procedures in stress urinary incontinence: A systemic review and meta-analysis of effectiveness and complications. BJOG. 2007; 114:522-531.

10. Barber MD, Kleeman S, Karram MM, et al. Risk factors associated with failure 1 year after retropubic and midurethral slings. Am J Obstet Gynecol. 2008; 199:666-670.

11. Murphy M, Heit MH, Fouts L, et al. Effect of anesthesia on void- 
ing function after tension-free vaginal tape procedure. Obstet Gynecol. 2003; 101:666-70.

12. Kim S, Bae J, Cho M, et al. Effect of preoperative flow rate on postoperative retention and voiding difficulty after transobturator tape operation. 2014; 55:190-5.

13. DeLancey JOL, Trowbridge ER, Miller JM, et al. Stress urinary incontinence: relative importance of urethral support and urethral closure pressure. Urology. 2008; 179:2286-90.

14. Ashton-Miller J, Delancey JOL. Functional anatomy of the female pelvic floor. Ann NY Acad Sci. 2007; 1101:266-96.

15. Barbic M, Kralj B, Cor A. Compliance of the bladder neck supporting structures: importance of activity pattern of levator ani muscle and content of elastic fibers of endopelvic fascia. Neurourol Urodyn. 2003; 22:269-76.

16. Mischinger J, Amend B, Reisenauer C, et al. Different surgical approaches for stress urinary incontinence in women. Minerva Ginecol. 2013; 65:21-28.

17. Stav K, Dwyer PL, Rosamilia A, et al. Repeat synthetic mid urethral sling procedure for women with recurrent stres urinary incontinence. J Urol. 2010; 183:241-246.

18. Abdel-Fattah M, Ramsay I, Pringle S, et al. Randomised prospective single-blinded study comparing 'inside-out' versus 'outside-in' transobturator tapes in the management of urodynamic stress incontinence: 1-year outcomes from the E-TOT study. BJOG. 2010; 117: 870-878.

19. Lazarou G, Miller C, Gupta N, et al. Intraoperative crede maneuver for tape adjustment during transobturator sling placement: does it improve continence. Female pelvic medicine and reconstructive surgery 2013; 6:369-372.

20. Takacs $P$, Medina CA. Tension-free vaginal tape: poor intraoperative cough test as a predictor of postoperative urinary retention. Int Urogynecol J. 2007; 18:1445-47.

21. Murphy M, Culligan PJ, Arce CM, et al. Is the cough-stress test necessary when placing the tension-free vaginal tape? Obstet Gynecol. 2005; 105:319-324.

22. Lavy Y, Lev-Sagie A, Hamani Y, et al. Cough stress test during the tension-free vaginal tape procedure: is it necessary? In Proceedings of the $32^{\text {nd }}$ AnnualMeeting of the International Continence Society, ICS Office Publications, Heidelberg, Germany, 2002.

23. Petri E, Ashok K. Complications of synthetic slings used in female stress urinary incontinence and applicability of the new IUGA-ICS classification. Eur J Obstet Gynecol. 2012; 165:347-51.

24. Ulmsten U, Henriksson L, Johnson P, Varhos G. An ambulatory surgical procedure under local anesthesia for treatment of female urinary incontinence, InternationalUrogynecology Journal and Pelvic Floor Dysfunction. 1996; 7:81-5

25. Schreiner L, Peterson TV, Karp D, Davila GW. Predictive factors for voiding dysfunction after transobturator slings. 2013; 35:290-4.

26. Kawashima H, Hirai $K$, Okada $N$, et al. The importance of studying pressure-flow for predicting postoperative voiding difficulties in women with stress urinary incontinence: a preliminary study that correlates low Pdet $x$ Qave with postoperative residual urine. Urol Res. 2004; 32:84-8.

27. Dawson T, Lawton V, Adams E, Richmond D. Factors predictive of post-TVT voiding dysfunction. Int Urogynecol J Pelvic Floor Dysfunct. 2007; 18:1297-302.

28. Mostafa A, Madhuvrata P, Abdel-Fattah M. Preoperative urodynamic predictors of short-term voiding dysfunction following a transobturator tension-free vaginal tape procedure. Int J Gynaecol Obstet. 2011; 115:49-52

29. Lemack GE, Krauss S, Litman H, et al. Normal preoperative urodynamic testing does not predict voiding dysfunction after Burch colposuspension versus pubovaginal sling. J Urol. 2008; 180:2076-80.

30. Segal J, Steele A, Vassallo B, et al. Various surgical approaches to treat voiding dysfunction following anti-incontinence surgery. Int Urogynecol J Pelvic Floor Dysfunct. 2006; 17:372-7.

31. Viereck V, Rautenberg O, Kociszewski J, et al. Midurethral sling incision: indications and outcomes. Int Urogynecol J. 2013; 24:645-53.

32. Cam C, Karateke A, Sakall M. Validation of the short forms of Incontinence Impact Questionnaire (IIQ-7) and Urogenital Distress Inventory (UDI-6) in a Turkish Population. Neurourology Urodynamics. 2006; 26:129-133.

33. Heinonen $P$, Ala-Nissilä $S$, Räty $R$, et al. Objective cure rates and patient satisfaction after the transobturator tape procedure during 6.5-year follow-up. J Minim Invasive Gynecol. 2013; 20:73-8.

34. Domingo S, Alamá P, Ruiz N, et al. Transobturator tape procedure outcome: a clinical and quality of life analysis of a 1-year follow-up. Int Urogynecol J Pelvic Floor Dysfunct. 2007; 18:895-900.

\section{Correspondence}

Abdulmuttalip Simsek, MD (Corresponding Author) simsek76@yahoo.com

Bakirkoy Sadi Konuk Research and Training Hospital,

Department of Urology, Zuhuratbaba, Tevfik Saglam

Cad. NO:11 Bakirkoy, Istanbul, Turkey

Sinan Levent Kirecci, MD

Goksel Bayar, MD

Kaya Horasanli, MD

Sisli Etfal Research and Training Hospital, Department of Urology, Turkey

Faruk Ozgor, MD

Zafer Gokhan Gurbuz, MD

Haseki Research and Training Hospital, Department of Urology, Turkey 